\title{
The Path of Least Resistance: Projections of Social Inequalities as a Result of Climate Change in the United States
}

\author{
Affiliations: \\ ${ }^{* 1,2}$ Mathew E. Hauer \\ Department of Sociology \\ Center for Demography and Population Health \\ Florida State University \\ Tallahassee, Florida \\ mehauer@fsu.edu \\ ${ }^{1}$ R. Kyle Saunders \\ Department of Sociology \\ Florida State University \\ Tallahassee, Florida \\ ${ }^{3}$ Daniel Shtob \\ Department of Sociology and Environmental Studies Program \\ University of Oregon \\ Eugene, Oregon \\ *Corresponding Author
}

Acknowledgements: The authors would like to thank P. Homan, M. Taylor, D. Rohlinger, R. Liévanos, and N. Theis for their insightful feedback that improved our manuscript.

\begin{abstract}
:
Environmental inequality and environmental racism are well-documented in the United States (U.S). Unlike typical approaches where sociologists investigate environmental inequality as it exists in the present, climate change hazards are known to compound over time, worsening in the future. Although the current demographic characteristics of the U.S. are known, here we account for the anticipated demographic changes likely to occur this century that could substantially compound climate inequality in the U.S. We use sea-level rise as an example of compounding environmental risk to uncover the magnitude of future inequalities. Specifically, we analyze how climate change may amplify inequalities in the future by disproportionately impacting presently vulnerable groups (e.g., by race, sex, and age). We find that communities of color and the elderly will face intensified impacts of sea-level rise by the end of the century. These processes of environmental inequality formation would go undetected using current, rather than projected, demographic data. Our results suggest climate change will continue to develop as a source of inequality this century and beyond, transmitting inequality across time and saddling future generations with environmental and social disadvantage. Our results, therefore, represent an important new approach to predict inequality formation in the distant future.
\end{abstract}

Keywords: vulnerable populations, demographic shift, racial inequality, environmental justice, climate change, sea-level rise 


\section{Introduction}

Climate change is one of the most pressing challenges of the $21^{\text {st }}$ century. Extreme heat, sealevel rise, increasing droughts and wildfires, and significant economic damage are but a few impacts expected of climate change this century (Field 2014). Moreover, these impacts are predicted to be unequally distributed across countries and populations by class, age, sex, and race, amplifying inequalities (Harlan et al. 2015) by disproportionately impacting marginalized peoples and groups (Field 2014; Skoufias 2012). Reducing the hardships and inequalities wrought by climate change requires concerted efforts to reduce carbon emissions, adapt to the potentially disastrous consequences, and to do so in an equitable manner.

Sociologists who study climate change draw on the lengthy literature surrounding environmental inequality and environmental racism - defined as environmental hazards that disproportionately impact or disadvantage groups, individuals, or communities of color - in their analyses. Environmental racism and other forms of environmental injustice and inequality are welldocumented in the U.S. The study of the effects of these phenomena has led to the development of important theoretical frameworks for understanding and dismantling them, such as the critiques of racial capitalism and critical environmental justice (Faber and Krieg 2002; Hurley 1995; Krieg 1998; Mitchell and Norman 2012; Mohai 1996; Muller, Sampson, and Winter 2018; Pellow 2017; Pulido 2017).

While climate change is expected to exacerbate environmental inequality and environmental racism, studies typically focus on how future climate change could perpetuate these inequalities within the context of present population distributions (e,g., Emrich and Cutter 2011; Frazier et al. 2010; Hsiang et al. 2017; Martinich et al. 2013). Yet with climate impacts expected to worsen as we approach the end of the century due to intensified warming, the direst climate impacts may 
not depend on present conditions. Rather, they will depend on future conditions. By focusing on current populations, the potential for emerging environmental inequality formation (Pellow 2000) could go undetected. Marginalized groups could face the brunt of climate change in unexpected ways based on the changing features of the U.S. population that would encounter future climate conditions. The well-documented population growth of both communities of color and the elderly in the U.S. (Colby and Ortman 2017), as well as evidence of existing climate inequality, suggests that future generations of these groups are likely to be disproportionately impacted by future climate change impacts.

In this article, we couple existing theory in environmental sociology and environmental justice studies (Pellow 2000, 2017; Schnaiberg 1980; Schnaiberg and Gould 1994) with recently published long-range population projections (Hauer 2019) to argue that climate change will both exacerbate existing inequalities and accelerate the formation of new inequalities across time and space. Specifically, we demonstrate how climate change will amplify inequalities by disproportionately impacting vulnerable groups in the future (e.g., by race, sex, and age). This represents a new approach to modeling long-term projections of inequality formation.

Developments in environmental sociology and the study of environmental justice inform our work by capturing how environmental and social conditions may synergistically promote inequality (Pellow 2017; Pellow and Brulle 2005; Pellow and Nyseth Brehm 2013), as well as how the fervent pursuit of economic growth may increase exposure to climate hazards for specific groups (e.g., Martinich et al. 2013). Social and political forces influence where individuals presently reside; for example, residential segregation, racially- and economicallyfocused zoning laws, and development policies influence where populations are concentrated. In turn, residential conditions and growth patterns may influence who is impacted the most by 
climate change, in part due to differential growth rates among demographic groups and in part because such changes may result in differential risk among demographic groups by virtue of where different groups tend to live.

To demonstrate climate change's importance to the development of contemporary environmental inequality, we use future sea-level rise, a broadly accepted outcome of climate change, as an example of how climate change will exacerbate existing inequalities among different of demographic groups (e.g., by race, sex, and age). Sea-level rise is widely expected to spur population migration and displacement (Hauer 2017; McGranahan, Balk, and Anderson 2007; Nicholls Robert J. et al. 2011, Elliott and Howell 2017), reduce property values in flood prone areas (McAlpine and Porter 2018), increase disastrous storm surges (Kossin 2018), and generally disrupt vital social systems (Suarez et al. 2005). Climate change impacts like these interact with race, class, sex, age, and other socio-demographic factors to perpetuate and reproduce longstanding social inequalities (Elliott and Pais 2006; Howell and Elliott 2019; Loughran and Elliott 2019; Zehr 2015). Taken together, these observations suggest the likelihood that climate change and sea-level rise will continue to interact with coastal demography to pattern future environmental inequality.

In fact, we find communities of color and the elderly_-groups particularly vulnerable to environmental change-will face the brunt of the impacts of sea-level rise in the U.S. Using current rather than future projected demographic data, the environmental inequalities we uncover would go undetected. Our results suggest that climate change will continue to emerge as a primary source of environmental inequality during this century and beyond: its effects will intensify not only because of increased intensity of geophysical effects such as flooding or extreme temperatures, but also because proportionately more members of vulnerable groups will 
be in harm's way. Assuming that structural inequality persists, this demonstrates that the injustice associated with coastal climate impacts will likewise intensify. In this way climate change will transmit inequality across time, saddling future generations with new forms of environmental and social disadvantage at a scale that could not be reasonably predicted using either present sea levels or present demographic patterns. Moreover, our approach represents a new approach to using advanced demographic analyses to predict inequality formation in the distant future. It therefore has a variety of uses and applications not only within environmental sociology and demography in the U.S., but across fields, disciplines, and regions of the globe.

\section{Literature Review}

For much of its history, environmental sociology has concerned itself with remedying the false assumption that social issues and environmental issues are separate and distinct. Fundamental to this project is the idea that sociologists are both competent and uniquely positioned to understand and analyze "environmental" issues (Catton and Dunlap 1978; Dunlap and Catton 1979). Due to its anthropogenic nature and global consequences, climate change presents an ideal opportunity to deploy sociology for the purpose of understanding how inequality develops at the intersection of social and environmental systems. Indeed, environmental sociologists have grappled with issues including the causes of climate denial (e.g., Dunlap and McCright 2011; Norgaard 2011), the anthropogenic sources of climate change (e.g., York, Rosa, and Dietz 2003), and how climate change interacts with questions of inequality and justice (e.g., Parks and Roberts 2010; Roberts and Parks 2009). Climate change is, to put it bluntly, a social issue.

\subsection{Environmental Sociology and Environmental Justice.}


A core mission of environmental sociology is to understand how social and environmental systems interact in ways that have the capacity to amplify both environmental harm and inequality over time. One theoretical viewpoint—-the treadmill of production—uses the metaphor of an ever-accelerating treadmill to illustrate how capitalism is a significant factor driving environmental harm through the consumption of resources and production of waste (Schnaiberg 1980; Schnaiberg and Gould 1994). The treadmill acknowledges that global capital investment generally leads to higher demands upon natural resources, and that each round of investment intensifies these demands, thereby weakening environmental conditions as well as employment conditions for production workers (Gould, Pellow, and Schnaiberg 2004). The accelerating rate of consumption of natural resources in these production processes results in environmental hazards (e.g., toxic waste). Among other features, the treadmill approach illustrates the longstanding concern in environmental sociology about the development of environmental harm over time.

Human exposure to environmental harm also has a spatial component that, when combined with this temporal component, provides analytical insight into how environmental inequality and injustice manifest in practice. Marginalized communities consistently face greater exposure to environmental hazards, demonstrating that overall environmental harm is only one component of socio-environmental analysis (Bullard and Wright 2012; Jesdale, Morello-Frosch, and Cushing 2013; Taylor 2014). Rather, environmental risks are not equally distributed among populations residing in different areas, and exposure to these risks may reflect systems of structural inequality (Pulido 2000, 2017). This may institutionalize and spatialize discrimination on the basis of race, class, and other factors, exposing already marginalized populations to a disproportionate share of environmental harms ranging from pollution to natural disasters 
(Conley 2010; Dreier, Mollenkopf, and Swanstrom 2004; Howell and Elliott 2019; Liévanos

2017; Massey and Denton 1993; Oliver and Shapiro 2013; Sharkey 2013; Tierney 2007, 2015).

The idea that the production of environmental harm intensifies over time, combined with the spatial reality of greater exposure to environmental risk and hazard, illustrates the importance of approaches that take both time and space into consideration. One reason for the spatial heterogeneity in environmental exposure is that formal and informal policies of segregation may result in differential exposure to environmental hazards - especially when influenced by racism by constraining residential choice (Dreier et al. 2004; Sharkey 2013). In short, environmental harms may both become worse and become more concentrated over time; whether they do become more concentrated depends in part on the social processes that regulate how populations move in and out of affected space.

Figure 1 is a conceptual model of our argument. First, environmental harm is largely created and perpetuated through policy that focuses on creating economic growth. In our case, this results in climate change itself, as well as sea-level rise. Components A, B, and C show a process of how individuals' residential locations are not evenly distributed (A), and in turn, how a constrained ability to choose one's area of residence (B), is related to discriminatory policy (C). The pursuit of economic growth leads to the production of climate "bads" (e.g., exposure to environmental risk or hazard) (1), which is the consequence of the preference for economic growth. The treadmill of production also feeds back into the production of climate "bads" over time, as the treadmill necessarily accelerates, consuming additional resources and justifying riskier or more hazardous "choices." Additionally, choices made in service of economic advancement, over time, also have spatial consequences that are converted into social inequality by the uneven patterning of populations across landscapes, including through segregation in its past, present, 
and future forms (Gotham 2002; Pellow 2017). Put another way, understanding that residential decisions are constrained by structural forces and not the result of individual free will suggests that "who lives where," and what environmental risks exist there, are social processes that are both the result of, and generative of, inequality.

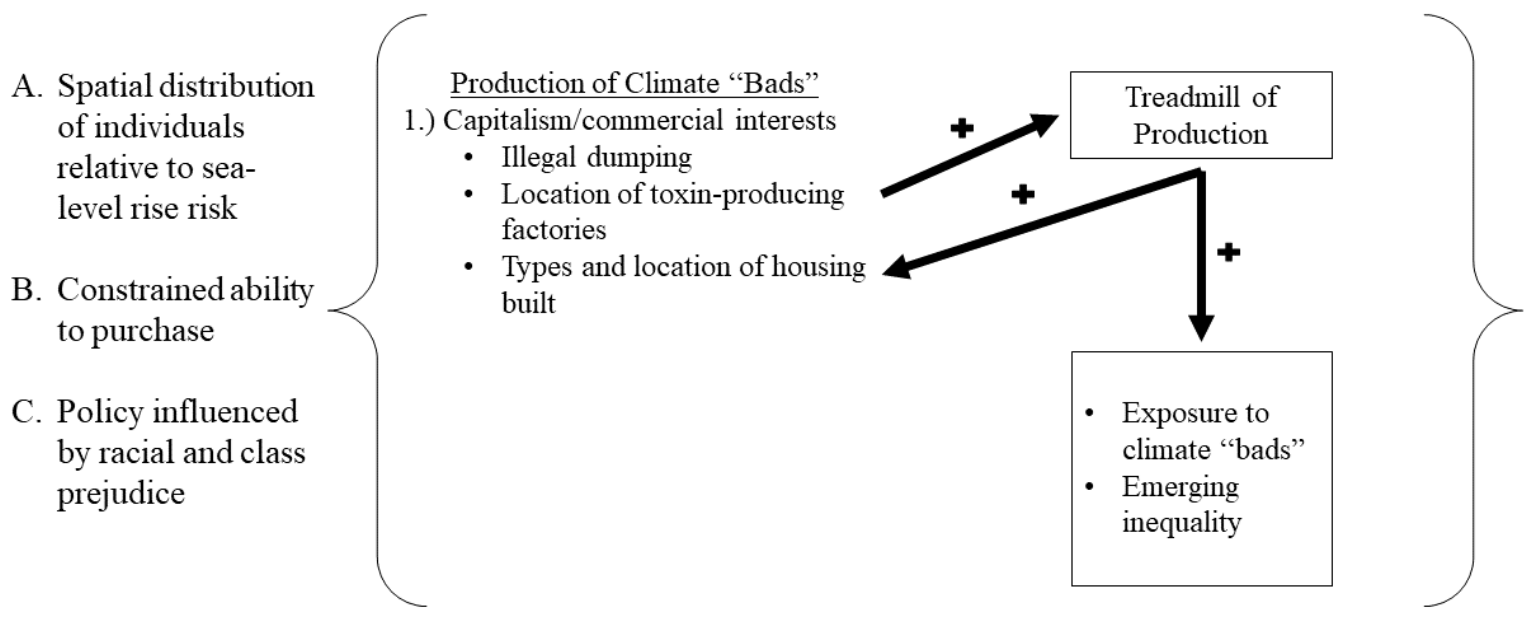

Figure 1. Proximity to Environmental Harm.

Race and class are two significant factors to consider when exploring differential exposure to these hazards (Liévanos 2017). There is evidence that areas with larger proportions of people of color have significantly more exposure to environmental harm (Bullard 1983; Justice 1987). This relationship is compounded by the facilities also most likely to be in areas of lower social and economic capital (i.e., low voting behavior, low wealth, lower homeownership) (Pastor, Sadd, and Hipp 2001). Combined with other forces such as gerrymandering (Dreier et al. 2004), white and middle-class flight to the suburbs (Faber and Krieg 2002), and racial discrimination (Hurley 
1995), this results in the communities of color being located in areas of concentrated segregation (Pellow 2004). Thus, intersecting cumulative disadvantage on racial and class lines effectively force people of color and less affluent people into areas of greatest environment risk (Dreier et al. 2004; Rubinowitz and Rosenbaum 2000; Sharkey 2013; Taylor and Fry 2012). By considering these types of structural concerns and their social and economic influence, this framework lends itself to understanding how macro-structural contexts (e.g., a coalition for economic growth) create localized inequalities (e.g., differential exposure to toxins) through discriminatory practices (e.g., residential segregation). This suggests the need for greater attention to the processes of how uneven exposure to environmental harm develops over both time and space.

Recent innovations in the study of environmental justice reflect these concerns and support the development of novel approaches to understand the formation of unjust exposure to environmental harms. Early, movement-based environmental justice efforts focused on proving the existence of environmental injustices such as disproportionate exposure to environmental harms in less affluent communities and communities of color, fighting identified injustice, and highlighting the importance of environmental justice itself, as it had historically been sidelined by mainstream environmental movements (Bullard 1983, 2018; Taylor 2000, 2014). Over time, theoretical approaches were developed that focused on the processes by which environmental inequality is formed, viewing this formation through a socio-historical lens (Szasz and Meuser 1997, 2000).

Environmental inequality formation, for example, represents a structural approach to understanding the socio-historical processes by which environmental inequality came to exist. Toward this end, it embraces multiple dimensions of potential marginalization with an eye 
toward both problem identification and problem solving (Pellow 2000). Building upon this diverse, processual view, Pellow (2017) argues - as part of his elaboration on critical environmental justice studies — for the development of multi-scalar approaches to environmental justice in which the processes of its formation are studied across a variety of spatial and temporal contexts. Coupled with acceptance of the foundational proposition that climate change is a justice issue (Harlan et al. 2015), these efforts support the co-development of our understanding of the future geophysical consequences of climate change, the social conditions with which they will interact, and how the combination of these factors may result in disproportionate exposure to environmental harm and risk on the basis of race, class, or other group memberships.

Hardy, Milligan, and Heynen (2017) extend the general socio-historical analysis of racialized exposure to environmental harms specifically into the coastal context through what they term coastal racial formation. Drawing upon Omi and Winant's (2014) racial formation theory as well as contemporary environmental justice studies, they observe that a deep appreciation of the racialized history of coastal development is necessary to understand contemporary exposure to climate risk and to advance coastal climate science. Similarly, studies in the sociology of natural disaster have developed the importance of disasters - an unfortunate result of both climate change and sea-level rise — and inequality formation, including on the basis of race and class (Elliott and Pais 2006), on the basis of wealth creation and destruction (Howell and Elliott 2019), on the basis of gender (Nagel 2012), and as a broad consequence of political economic exploitation (Klein 2018; Tierney 2007, 2015). Yet these studies—like the vast majority of social science efforts in the rapidly growing field of climate change research and environmental justice generally — tend to employ historical data, analyzing past events and current circumstances in order to (presumably) suggest ways to solve current or future problems. 
Here, we depart from traditional uses of these frameworks within environmental sociology and environmental justice, to examine future environmental inequality resulting from a broader environmental issue: climate change. Specifically, we demonstrate how climate changedependent sea-level rise is likely to disproportionately impact already marginalized communities. In turn, this may help predict the compounding effects of cumulative disadvantage over the course of the next century and to suggest ways to develop more just residential and climate policy.

We use the example of sea-level rise to bring an outcome of climate change to bear on the creation, magnification, and perpetuation of inequalities. Without exploring how climate change may disproportionately push marginalized groups further into disadvantage, we risk blindly stumbling into a future wrought with amplified transmission of inequality in coastal areas. Thus, our contribution is substantive and theoretical. Connecting this project to the temporal aspects of the treadmill of production allows for a new forward-looking view on the creation of environmental harm. The links to recent innovations in environmental justice, environmental inequality, coastal racial formation, and the study of disaster supports the integration of these fields with the demographic projections. Empirically, we use innovative population projections to provide evidence about how inequality may form within currently disadvantaged groups over time.

\subsection{Sea-Level Rise}

We consider sea-level rise a broad climate change impact as it is one of the best understood and well-documented implications of future climate change (Field 2014). Forty percent of the U.S. population lives in a National Oceanographic and Atmospheric Administration (NOAA) 
designated coastal community (Crossett et al. 2013) and sea-levels may rise as much as nine feet by 2100 (Kopp et al. 2017), threatening the displacement of millions of people in the U.S. (Hauer, Evans, and Mishra 2016; Strauss, Kulp, and Levermann 2015) and billions of dollars of coastal real estate (Heberger et al. 2011; McAlpine and Porter 2018). Additionally, adapting to sea-level rise is likely to cost billions of dollars in the U.S. alone (Huntington, Goodstein, and Euskirchen 2012). Policy prescriptions aimed at reducing inequalities based on present sociodemographic and environmental conditions could inadvertently exacerbate inequalities, rather than alleviate them, if socio-demographic change is unaccounted for (Hardy et al. 2017). Similarly, preemptive adaptation that fails to incorporate socio-demographic change could create maladaptation and perpetuate inequality.

While global greenhouse gas emissions driven by capitalism represent a macro-structural context of the treadmill of production, the inequalities created by climate change are often hyperlocalized in nature. For example, the state of Florida accounts for nearly half of the populations exposed to sea-level rise in the U.S. with Miami-Dade and Broward counties accounting for nearly $25 \%$ (Hauer et al. 2016). Thus, Florida - a state representing less than $10 \%$ of the U.S. populace - will be disproportionately impacted by sea-level rise.

Given the well-documented growth of racial minority groups and the elderly, we suspect that communities of color and the elderly will be disproportionately impacted by sea-level rise by the end of the century, representing an example of emerging climate change inequality formation. The environmental justice literature overwhelmingly focuses on the vulnerabilities and impacts of current populations. For example, scholars routinely calculate vulnerability indices such as the Social Vulnerability Index (SoVI) (Emrich and Cutter 2011) based on current populations. But populations are not static; they are called 'population dynamics', not 'population statics'. The 
processes of environmental harm creation represented by the treadmill of production do not operate only between capital and society in the present, but over time as well. In addition to the integration of the state of the art in meteorological or oceanographic projections and models, capturing the full effects of climate change requires the integration of the state of the art in population dynamics.

\section{Methods}

To investigate the potential inequalities climate change might exacerbate, we use recently published, detailed county-level population projections (Hauer 2019). These data project populations for eighteen five-year age groups (0-85+), two sex groups (Male and Female), and

four race groups (White NH, Black NH, Other NH, and Hispanic). These demographic population projections use cohort-change ratios (CCRs) and cohort-change differences (CCDs) (Hamilton and Perry 1962; Swanson, Schlottmann, and Schmidt 2010) in Leslie matrix projection models (Caswell 2001). We do note that the population projections do not account for potential racial identity changes over the life course - changes that are likely to occur (Alba 2018) - and a limitation in our analysis.

We briefly summarize Hauer's (2019) methods here.

Parsimonious applications of the traditional cohort-component model generally take the form of CCRs and CCDs (Hamilton and Perry 1962; Swanson et al. 2010):

$$
\begin{gathered}
C C R_{x, t}=\frac{{ }_{n} P_{x, t}}{{ }_{n} P_{x-y, t-y}} \\
{ }_{n} \hat{P}_{x, t}=C C R_{x, t} \times{ }_{n} P_{x-y, t}
\end{gathered}
$$




$$
\begin{gathered}
C C D_{x, t}={ }_{n} P_{x, t}-{ }_{n} P_{x-y, t-y} \\
{ }_{n} \hat{P}_{x, t}=C C D_{x, t}+{ }_{n} P_{x-y, t}
\end{gathered}
$$

Where ${ }_{n} P_{x, t}$ is the population aged $x$ to $x+n$ in time $t$ and ${ }_{n} P_{x-y, t}$ is the population aged $x-y$ to $x+n-y$ in time $t$ and $y$ refers to the time difference between time periods. Both the population aged 0-4 and the open-ended age interval (85+) receive special consideration as there is no age group that precedes the population age $0-4$ nor proceeds the population aged $85+$. See Hamilton and Perry (1962) and Hauer (2019) for details for handling these age groups in CCR models. Future populations are thus either the product (CCRs) or additive (CCDs) of the change between two periods.

CCRs/CCDs were calculated for each age, sex, race, county combination using data from the National Vital Statistics System (NVSS) U.S. Census Populations with Bridged Race Categories. Racial categorizations in the U.S. change over time and the National Center for Health Statistics collapses or bridges the thirty-one race categories used in Censuses 1990, 2000, and 2010 to four race groups (White, Black, American Indian/Alaska Native, and Asian/Pacific Islander) and two ethnic groups (Hispanic and Non-Hispanic). Hauer then collapsed these into four race/ethnic groups (White Non-Hispanic, Black Non-Hispanic, Other Non-Hispanic, and Hispanic) due to small cell sizes in sparsely populated counties.

The CCRs and CCDs for each age group $a$, race group $r$, sex group $s$, and county $c(\mathrm{n}=336,024$ age, sex, race, county combinations) were projected using autoregressive integrated moving average (ARIMA) models within an $\operatorname{ARIMA}(0,1,1)$ model, equivalent to a simple exponential smoothing model. 
The projected CCRs/CCDs populate Leslie matrix models such that counties projected to increase utilize CCDs and counties projected to decrease utilize CCRs. Blended linear/exponential projection techniques outperform strictly linear or strictly exponential population models (Wilson 2016). An ex-post-facto error analysis of these population projections demonstrated reasonable accuracy, on par with other cohort-component projections.

Hauer (2019) controlled the resulting projections to the Shared Socioeconomic Pathways (SSPs) (Jiang 2014; O’Neill et al. 2014, 2017; Samir and Lutz 2017). The SSPs, as their name suggests, represent possible socio-economic scenarios that couple potential challenges for reducing carbon emissions with challenges for adapting to climate change impacts. An international team of climate modelers, economists, energy systems modelers, and demographers produce the socioeconomic pathways to (1) derive emission scenarios for use in climate change projections and (2) use the pathways to evaluate climate change impacts. They provide a common "shared" set of population projections for various emission scenarios and climate impacts, ensuring more comparability across both physical and social science surrounding climate change. There are five SSPs, representing a range of possible mitigation and adaption possibilities. We use SSP2, colloquially named "Middle of the Road" as SSP2 represents the most likely future with modest challenges to both mitigation and adaptation.

Sea-level rise will have various impacts and hazards on coastal communities, including but not limited to, conversion of habitable dry-land to inhabitable water (called inundation), increased storm surges, reduced property values, and economic damages (Nicholls et al. 2011). These impacts vary within coastal areas, with those closest to the shoreline most at-risk to inundation while those more distant from the shoreline might experience economic damages and reduced property values (Hsiang et al. 2017; McAlpine and Porter 2018). We do not model these impacts 
directly, but rather situate the changing demographics of the coastal U.S. within the contexts of vulnerability to sea-level rise associated hazards.

Hauer's (2019) set of county-level population projections include the entire U.S. For this paper, we are only interested in counties impacted by sea-level rise. We subset the county population projections to only those counties that will be impacted by up to nine feet of sea-level rise by $2100(n=437)$.

\section{Results}

\subsection{Race/ethnic}

We find that coastal communities in the U.S. will be considerably more diverse by 2100 than they are today (Figure 2 and Table 1). Currently, the U.S.s' coastline is majority White NH, with more than $50 \%$ of the population in that race/ethnic group. If one were to simply look at the current coastal demographics, it would be easy to conclude that sea-level rise will not exacerbate racial inequalities and it is the White $\mathrm{NH}$ population that will face the brunt of sea-level rise impacts. This demographic change in exposure to sea-level rise would go undetected if we use only current populations instead of projected populations. Populations, however, are not static. Demographic change in coastal communities will likely lead to a White NH population that will dwindle - both in absolute numbers and as a proportion of the total population - by 2100 (Table 1). Instead, it is clear communities of color will face the brunt of sea-level rise impacts.

All non-White race/ethnic groups are projected to increase - both in absolute numbers and as proportions of the total population - as the century progresses. By 2100, the White NH population is projected to account for just over one-fourth of the U.S. coastal population - a 
decline of more than 20 percentage points and more than 13 million persons. Conversely, the Hispanic population is likely to increase by more than $136 \%$ by 2100 , accounting for nearly $40 \%$ of the U.S. coastal population.

This shift toward an increasingly diverse U.S. coastline is not limited to specific areas. Figure 3 shows the geographic distribution of race in the coastal U.S. in 2020 and projected in 2100 as a bivariate choropleth. The dominant race/ethnic group in each county is uniquely colored and the deepness of the color corresponds with the $\%$ of the population the dominant race/ethnic comprises. In 2020, the U.S. coastline is dominated by White, NH populations with most coastal counties exhibiting $75 \%+$ of their population as White, $\mathrm{NH}$, as exhibited the dark-blue color in the majority of counties. Only pockets of counties in parts of California, southern Texas, and south Florida are dominantly Hispanic, but decidedly less dominant than the White, NH populations, as exhibited by the lightly shaded browns. Alaska and Hawaii contain significant populations that are Native American, Pacific Islander, and Asian race/ethnic groups. Isolated pockets of Black, NH dominance are also found in parts of the U.S. south.

By 2100, however, the dark blue counties indicating a White, NH dominance are considerably reduced in number, reduced in hue (suggesting a smaller White, $\mathrm{NH}$ dominance by 2100), and many areas across the entire coastline contain significant Hispanic majorities - especially in the Northeast and California.

Who will reside in the communities most impacted by sea-level rise? If one were to simply examine the demographics of today, it would be the White, $\mathrm{NH}$ population. However, when demographic change is accounted for, those who will be most impacted by sea-level rise will be communities of color. 
Table 1. Projected Populations in the 437 U.S. counties impacted by 9 ft of sea-level rise or less.

\begin{tabular}{|c|c|c|c|c|}
\hline Race & $\begin{array}{l}\text { Population } \\
2020\end{array}$ & $\begin{array}{l}\text { Population } \\
2100\end{array}$ & $\begin{array}{l}\text { Numeric } \\
\text { Change }\end{array}$ & $\begin{array}{l}\text { Percentage } \\
\text { Change }\end{array}$ \\
\hline Black, NH & $19,981,597$ & $28,799,447$ & $8,817,851$ & $44 \%$ \\
\hline Hispanic & $31,913,644$ & $75,209,244$ & $43,295,600$ & $136 \%$ \\
\hline Other, NH & $15,150,139$ & $34,610,358$ & $19,460,219$ & $128 \%$ \\
\hline White, NH & $68,694,545$ & $55,123,281$ & $-13,571,264$ & $-20 \%$ \\
\hline
\end{tabular}
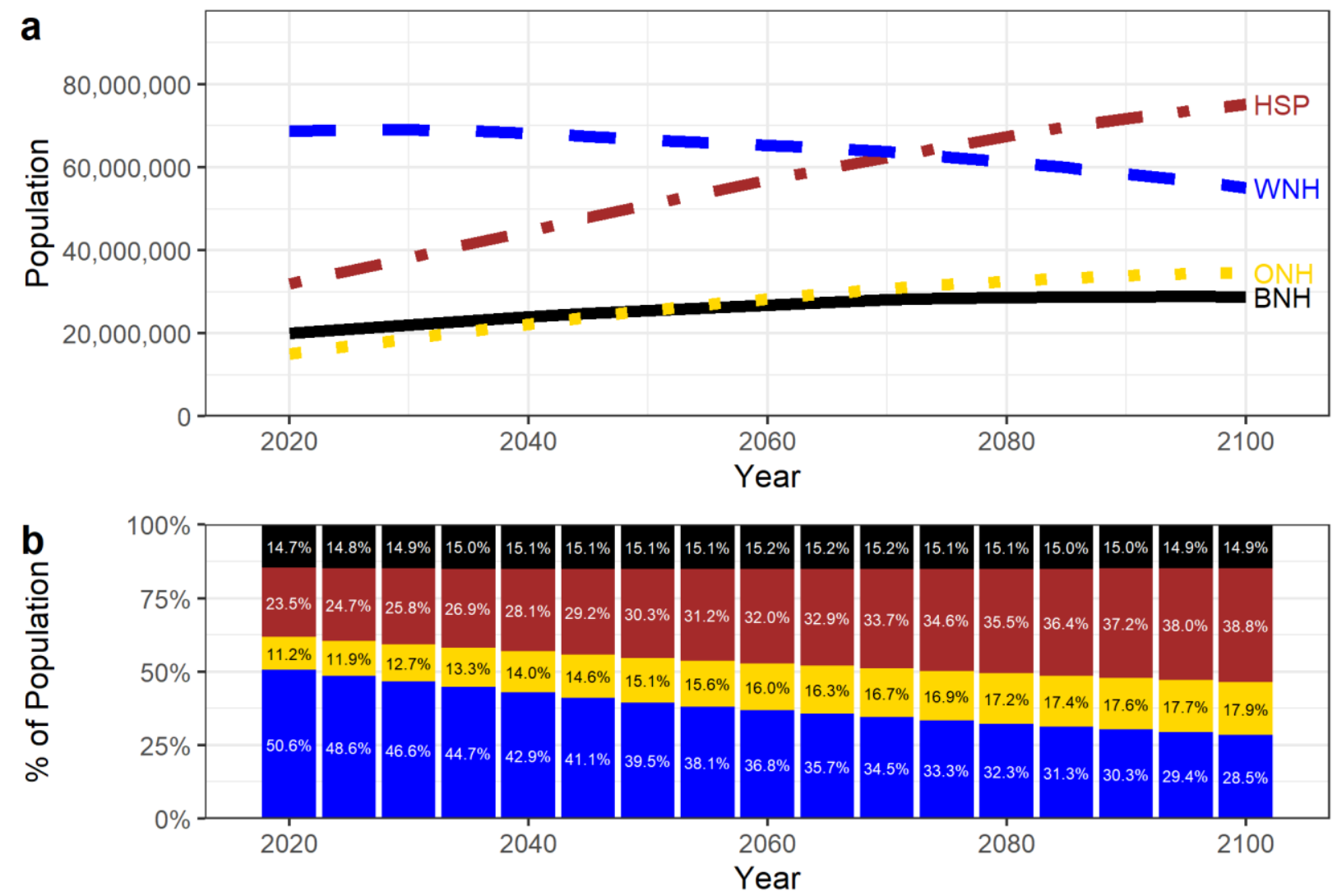

RACE $\square$ Black, NH $\square$ Hispanic $\quad$ Other, NH $\square$ White, NH

Figure 2. Projected populations by race in the 437 coastal U.S. counties impacted by $9 f$ of sea-level rise or less. (a) Shows numeric population changes and (b) shows the relative distribution of population. Sea-level rise will decreasingly impact White $\mathrm{NH}$ populations over time and increasingly impact communities of color. 
Coastal Race/ethnic Composition, 2020

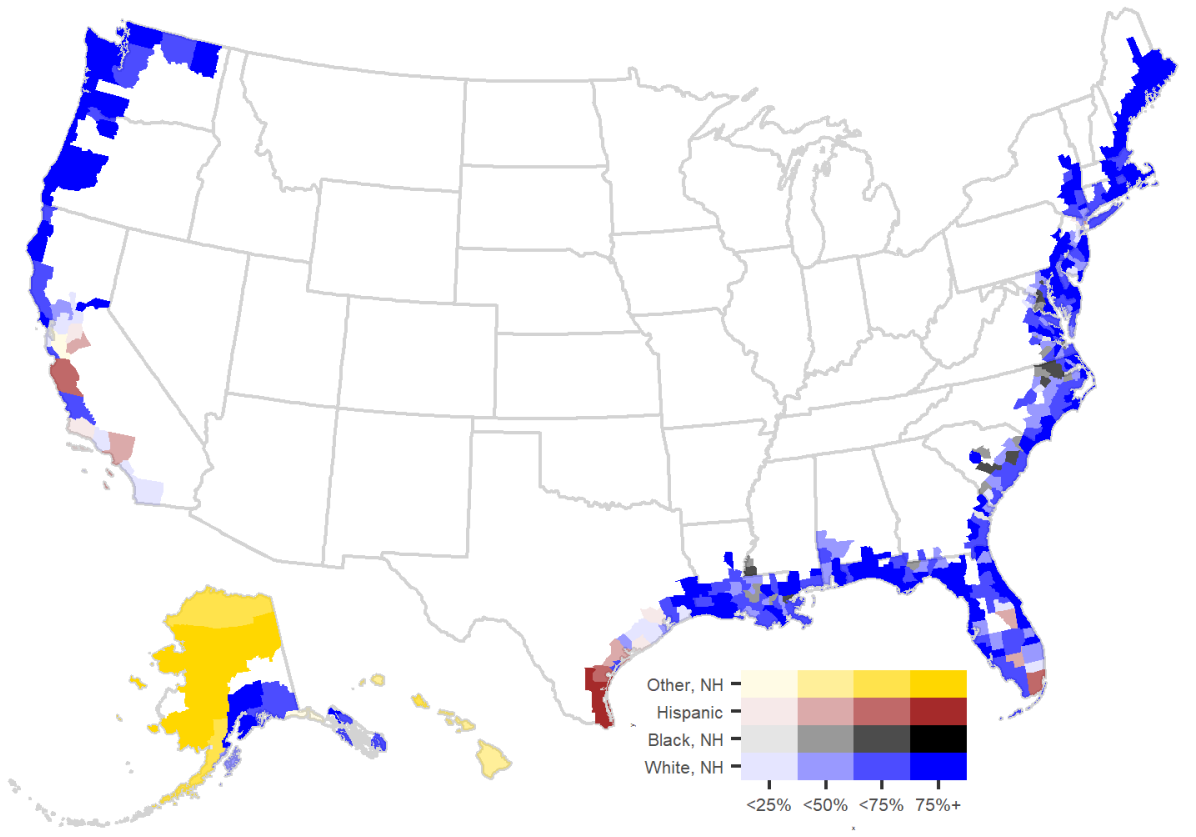

Coastal Race/ethnic Composition, 2100

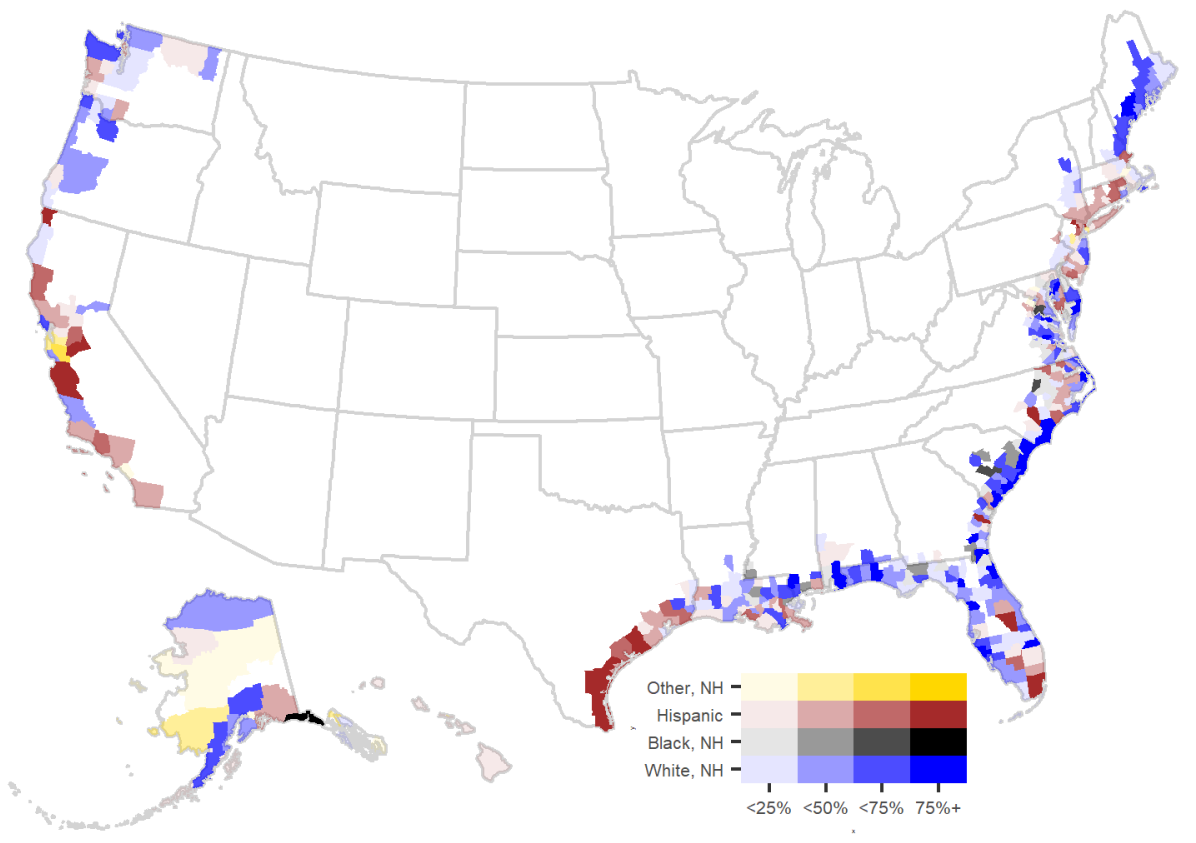

Figure 3. Racial Composition of the Coastal US in 2020 and 2100. The main color for each race group represents the largest race/ethnic group in each county and the hue represents the percentage of the total population that race/ethnic group comprises. 


\subsection{Age}

Additionally, the coastal communities of 2100 are likely to be considerably older than the present (Figure 4). Much like with race/ethnic changes, these impacts are undetected if demographic changes are left unaccounted. Today, the U.S. coast contains approximately 21 million people over the age of 65 , representing $16 \%$ of the coastal population. However, by 2100 the population over the age of 65 is projected to more than triple to nearly 70 million people and will account for $36 \%$ of the coastal population. This would increase the $65+$ age cohort from approximately 1 in every 6 coastal residents to more than 1 in every 3 . This is a significant demographic shift from a relatively youthful coastal population to a decidedly more elderly population. Using Japan as an example to put this aging shift in perspective, the population aged $65+$ in Japan is $26 \%$ the country's population. The coastal U.S. will be decidedly older than Japan is today - the country with the oldest age structure in the world.

For nearly every age group below age 40, the projected populations exhibit very little change. On the other hand, each age group above age 40 shows much larger growth. The coastal communities of 2100 are likely to be populated by considerably older residents, with the openended age interval (85+) showing the greatest numerical and percentage increase in population. Older women (in particular, women aged $85+$ ), represent the most population increase by the end of the century. These changes are substantial demographic changes, shifting who will be impacted by sea-level rise to a considerably older population. 


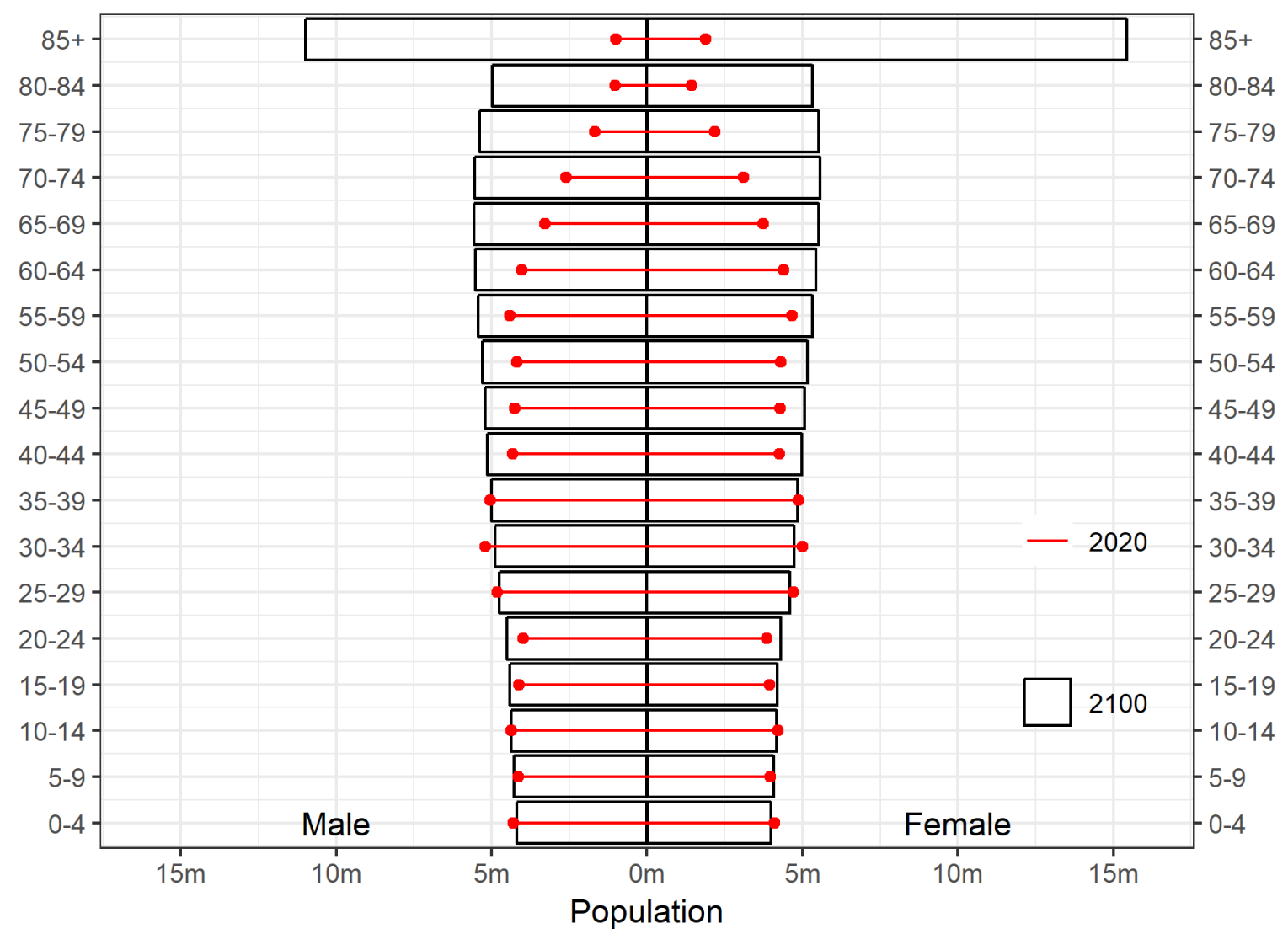

Figure 4. Population pyramid projections for the 437 coastal US counties. The population age distribution in 2010 is shown with the lollipop lines. The projected population in 2100 is shown in the hollow boxes.

This demographic shift to older populations is especially profound in the counties most exposed to sea-level rise. In this paper, we do not measure inundation risk to gauge the counties most exposed to sea-level rise. Hauer, Evans, and Mishra (2016) published estimates of the populations at-risk of displacement in the continental U.S. counties impacted by up to six feet of sea-level rise. We use their supplementary table 2 to identify the twenty-five counties containing the most people who could be displaced by six feet of sea-level rise by 2100 . We then calculate the median ages in 2020 and 2100 for these counties.

Figure 5 shows the median ages in 2020 and 2100 for the twenty-five most impacted counties, according to Hauer, Evans, and Mishra's supplementary table 2. Rather tremendous aging is 
expected in this set of counties. Of the most impacted counties, Collier County, Florida is expected to be the oldest by 2100 with a median age of 65.2 - an increase of nearly 20 years. Today, just four coastal counties have median ages in excess of 55 but, by 2100, fifty-one coastal counties will. To put this aging in perspective, $95 \%$ of U.S. counties today have median ages below 46. Yet by 2100,218 U.S. coastal counties - nearly $50 \%$ of coastal counties - will have a median age in excess of the $95^{\text {th }}$ percentile of median age in 2020 . What is considered "old" today will be commonplace by the end of the century.

Our results suggest that future populations impacted by sea-level rise will be considerably older compared to today. This is important because the elderly may have unique vulnerabilities (e.g., inability to migrate) to the effects of coastal climate change, although within this group exposure to vulnerability may be heterogenous (Wang and Yarnal 2012). 


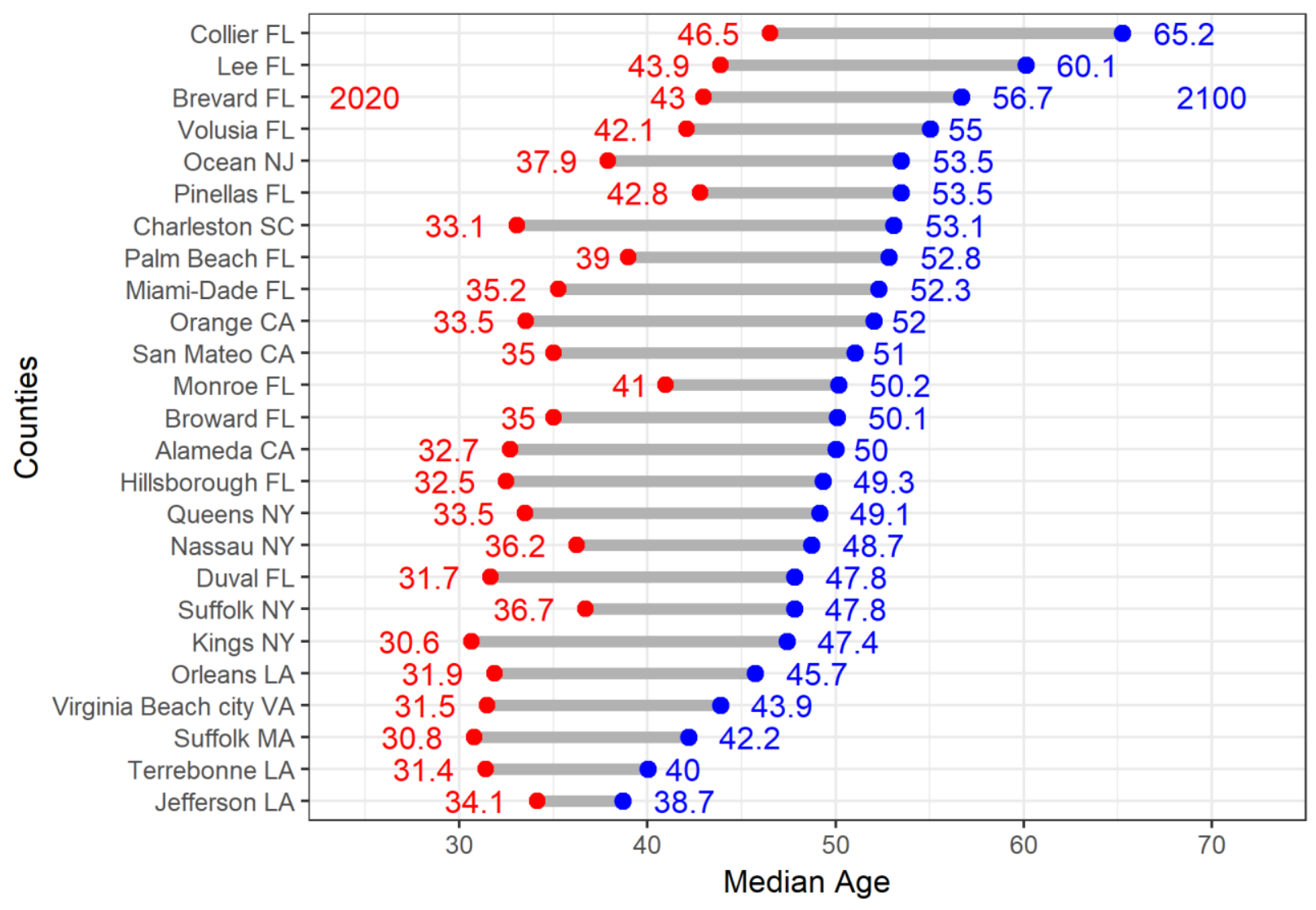

Figure 5. Median ages in 2020 and 2100 for the 25 most impacted US counties. These counties are the 25 most impacted by six feet of sea-level rise according to Hauer, Evans, and Mishra's (2016) supplementary table 2. The left dot corresponds to 2020 and the right dot to 2100.

\subsection{Sex}

In the previous two sub-sections we document the projected changes in race/ethnic and age groups in counties impacted by sea-level rise. In those sub-sections, we show how demographic change will lead to increased diversity and increased elderly populations by 2100 . Our results regarding sex composition in the coastal U.S. are markedly different (Figure 6). We find that coastal counties today contain approximately 2 million more women than men (68 million women to 66 million men) and this disparity grows by nearly 1 million women to 3 million more women than men by 2100 (98 million women to 95 million men). However, the ratio of women to men stays constant over the century at 1.03 woman per man. 
These results suggest women will be more impacted by sea-level rise compared to men, but only marginally so based on predictions of population composition. This is not to imply that the impacts of sea-level rise and associated hazards will manifest equally among sex or gender groups (nor that these two things are the same), as women may bear the brunt of the meteorological consequences of climate change like flooding, and their voices and suggestions may be unfortunately sidelined in conversations about appropriate adaptation (Nagel 2012). Rather, it reflects the observation that, unlike race and age, projections of sex composition of coastal areas through 2100 do not change substantially from the present.

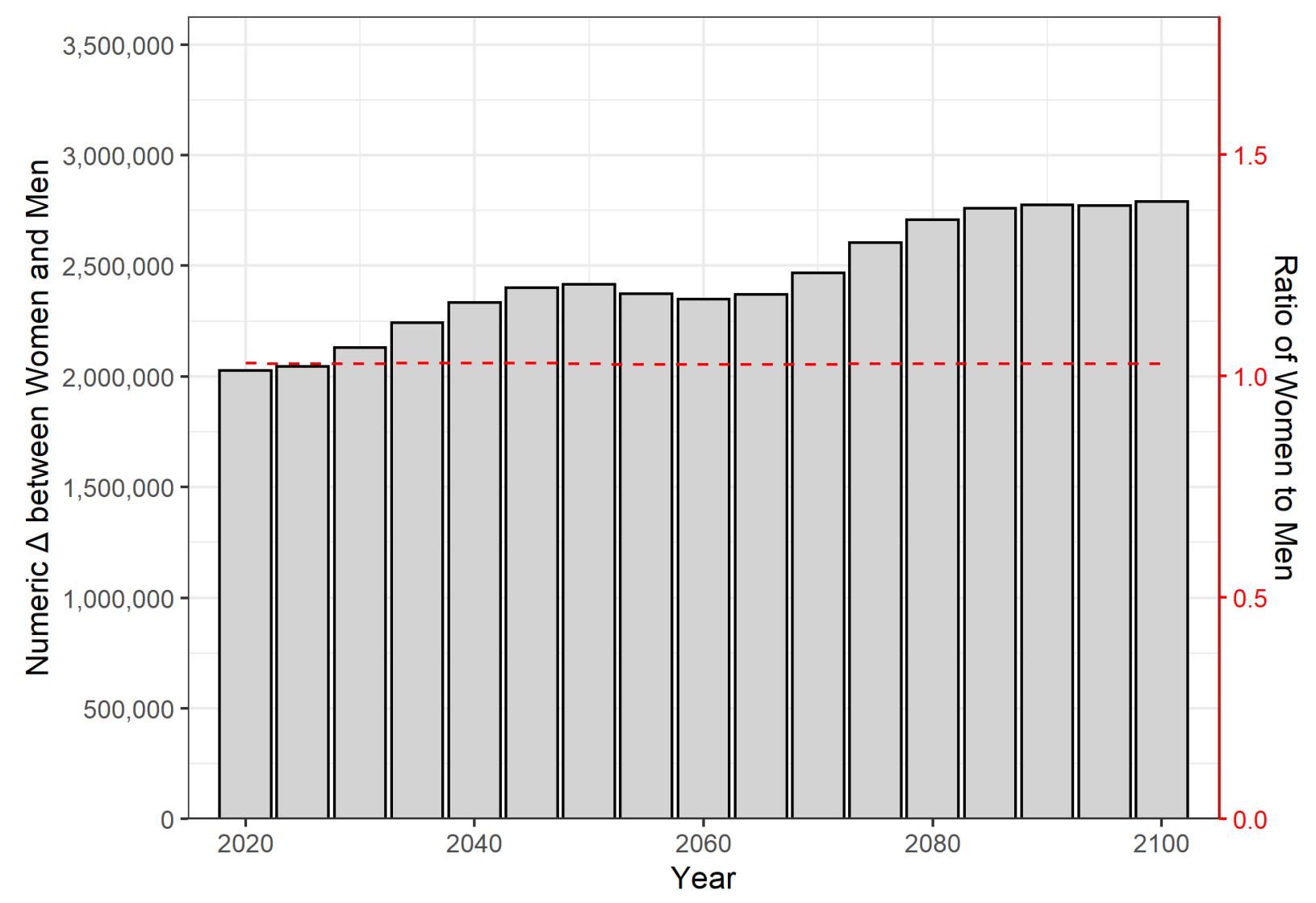

Figure 6. Projected sex differences in coastal US counties. Here we show the projected numeric difference in the male and female population (Women-Men) in bars on the left axis and the projected ratio of women to men (Women/Men) on the dashed line on the right axis. By 2100, there are projected to be 2.7 million more women than men in coastal areas 
compared to just 2 million in 2020. However, the ratio of women to men stays relatively constant at 1.03 woman per man.

\section{Discussion and Conclusion}

This paper provides empirical and theoretical advancements in our understanding of climate change related inequalities. We used published population projections to investigate how anticipated demographic changes will push climate impacts onto the elderly and communities of color. We use sea-level rise as an example of a broad climate impact, but these demographic trends are not unique to coastal areas - the entire U.S. is both aging and diversifying. If we were to investigate exposure to extreme heat or wildfires, for instance, we are confident the results would demonstrate similar environmental inequalities. Unmitigated climate change will become of the great sources of environmental inequality this century and beyond. The key is to use all resources at our disposal in order to analyze how, where, and when inequality will manifest.

As the treadmill framework suggests, environmental problems such as these may result from the uneven development of global capitalism, with important environmental justice consequences. On its surface, this uneven development takes on a spatial form. In the case of sea-level rise in the U.S., two U.S. counties (Miami-Dade and Broward counties), represent less than 2\% of the U.S. population but will account for $25 \%$ of those impacted by sea-level rise. This is the orthodox way in which some scholars deploy environmental frameworks to investigate environmental inequality and environmental racism. However, this orthodox treatment of climate change inequalities masks an important aspect: the future inequality wrought by the combination of global environmental change and demographic change. 
It is not simply the spatial manifestation of climate inequalities, but it is, importantly, also the temporal manifestation that is largely missed. Space, being produced by multiple competing processes, is continually created as an ongoing "process" where "what came earlier continues to underpin what follows" (Lefebvre and Nicholson-Smith 1991:229). For traditional environmental sociology, this involves historic practices like white-flight, racially-biased housing policies, discriminatory zoning laws, and business alliances that conspire with legal and illegal dumping and proximity to pollution sources to create environmental inequality and environmental racism (Brown and Mikkelsen 1997; Bullard 1993, 2018; Faber and Krieg 2002; Mitchell and Norman 2012). Space is not only created by historical and contemporary processes (“what came earlier") but is also shaped by future processes. Unequal spaces and the inequality they bring inherit the past but they also reflect future, imagined spaces. For instance, the environmental inequality and environmental racism presently experienced by communities of color is reflective of historic racist segregation, present (il)legal dumping, the continued burden of environmental externalities in those areas, and different versions of how environmental futures would, and will, unfold. The past, the present, and the imagined future continue to coproduce inequality.

The temporal aspect of climate inequality also provides opportunities to alleviate this inequality and helps us draw a road map toward better, more inclusive communities. As we demonstrate above, communities of color and the elderly will likely predominate in coastal regions in the future - but these groups that will occupy the future coast are likely not those most responsible for the environmental inequality they will inherit. Past spatial arrangements play key roles in the present spatial arrangements, which is why Lefebvre concludes that "the urban space is no differently defined in a socialist country than it is anywhere else" (Lefebvre and Nicholson- 
Smith 1991:113) due to urban spaces in socialist countries resulting from capitalist processes. Lefebvre suggests appropriation of capitalist spaces as a possible solution to addressing these inequalities, while others suggest art, combined with everyday lived experiences could contribute to more egalitarian spaces (Loftus 2012). These solutions, however, only address manifestations of the past that exist in the present. Instead, we suggest, through our analysis of sea-level rise inequalities, that we can also remake our communities through forward looking, rather than a backward-looking lens; that the future can shape the present.

If we are to eliminate inequality - all forms, not just environmental inequality - we must use all tools at our disposal. The creation of possible futures is another, often overlooked tool. Environmental inequality is the amalgamation of the historic, the present, and possible, probable, and preferred futures. By placing environmental inequality within the context of our future, we can bend our future to the paths that we wish to have; that our future can be that of hope and the alleviation of inequality rather than of despair and the reproduction of inequality.

What we offer here is one possible future: a future of the coastal U.S. as a realization of its current demographic path combined with our current path of global consumption practices. If we so choose to have a future in which climate change and sea-level rise perpetuate environmental inequality in communities of color and communities with a disproportionate number of elderly residents, then nothing should be changed; business can continue as usual. But if we choose to have a different future, then policies should be put in place to bend our current trajectory. This becomes increasingly important as we still have the power, the agency, and the ability to radically alter our potential future spaces toward the elimination of inequality. This is why predicting impacts on long timeframes is critically important. 
In the same way that the residues of our past, present, and future spaces have differing levels of impact on our current spaces, the scale of future spaces impacts our present space differently as well. The closer to the present a future space is, the less authority we have in our ability to change it. Like momentum that has built up in a moving object, the less momentum, the easier it is to change directions or to stop. In the same manner, our future trajectories have momentum attached to them. The longer we wait to reshape our potential future of climate inequality the less ability we have to alter this outcome.

Demography has a long history within the environmental literature of demographic change taking on a weaponized form (i.e. the "population bomb"), with the work of Malthus and Ehrlich representing some of the more famous examples. Alex Loftus in Everyday Environmentalism (2012) writes "too much environmental politics smacks of a catastrophism that quickly descends into ugly Malthusian claims" (p. X). We agree with Loftus in the abstract that most policy prescriptions involve some form of limiting population growth, and these can often take on racist or other ugly qualities that we expressly do not support. For example, we are not advocating antinatal population policies as an antidote for the environmental inequality that unmitigated climate change will create in the U.S. To advocate such policies in light our results would be to advocate for a reduction in non-white population growth - an abhorrent position to take. Rather, addressing these environmental inequalities will require 1) the reduction of carbon emissions to lessen the impacts of climate change and 2) the inclusion of more equitable adaptation policies, including within the context of longitudinal coastal and landscape planning. Our goal should be to "remake our cities in sensuously rich, [and] radically democratic and beautiful ways" (Loftus 2012:126). If we do not address these environmental inequalities, our future could be as ugly as our projections suggest. 


\section{References}

Alba, Richard. 2018. "What Majority-Minority Society? A Critical Analysis of the Census Bureau's Projections of America's Demographic Future.” Socius 4:2378023118796932.

Brown, Phil and Edwin J. Mikkelsen. 1997. No Safe Place: Toxic Waste, Leukemia, and Community Action. Univ of California Press.

Bullard, Robert D. 1983. "Solid Waste Sites and the Black Houston Community." Sociological Inquiry 53(2-3):273-88.

Bullard, Robert D. 1993. “The Legacy of American Apartheid and Environmental Racism.” . . John's J. Legal Comment. 9:445.

Bullard, Robert D. 2018. Dumping in Dixie: Race, Class, and Environmental Quality. Routledge.

Bullard, Robert D. and Beverly Wright. 2012. The Wrong Complexion for Protection: How the Government Response to Disaster Endangers African American Communities. NYU Press.

Caswell, Hal. 2001. Matrix Population Models. Wiley Online Library.

Catton, William R. and Riley E. Dunlap. 1978. "Environmental Sociology: A New Paradigm." The American Sociologist 13(1):41-49.

Colby, Sandra L. and Jennifer M. Ortman. 2017. "Projections of the Size and Composition of the US Population: 2014 to 2060: Population Estimates and Projections."

Conley, Dalton. 2010. Being Black, Living in the Red: Race, Wealth, and Social Policy in America. Univ of California Press.

Crossett, Kristen, Brent Ache, P. Pacheco, and K. Haber. 2013. "National Coastal Population Report, Population Trends from 1970 to 2020." NOAA State of the Coast Report Series, US Department of Commerce, Washington.

Dreier, Peter, John H. Mollenkopf, and Todd Swanstrom. 2004. Place Matters: Metropolitics for the Twenty-First Century. University Press of Kansas.

Dunlap, R. E. and W. R. Catton. 1979. "Environmental Sociology.” Annual Review of Sociology $5(1): 243-73$.

Dunlap, Riley E. and Aaron M. McCright. 2011. "Organized Climate Change Denial.” The Oxford Handbook of Climate Change and Society.

Elliott, James R. and Jeremy Pais. 2006. "Race, Class, and Hurricane Katrina: Social Differences in Human Responses to Disaster." Social Science Research 35(2):295-321. 
Emrich, Christopher T. and Susan L. Cutter. 2011. "Social Vulnerability to Climate-Sensitive Hazards in the Southern United States." Weather, Climate, and Society 3(3):193-208.

Faber, Daniel R. and Eric J. Krieg. 2002. "Unequal Exposure to Ecological Hazards: Environmental Injustices in the Commonwealth of Massachusetts." Environmental Health Perspectives 110(suppl 2):277-88.

Field, Christopher B. 2014. Climate Change 2014-Impacts, Adaptation and Vulnerability: Regional Aspects. Cambridge University Press.

Frazier, Tim G., Nathan Wood, Brent Yarnal, and Denise H. Bauer. 2010. "Influence of Potential Sea Level Rise on Societal Vulnerability to Hurricane Storm-Surge Hazards, Sarasota County, Florida." Applied Geography 30(4):490-505.

Gotham, Kevin Fox. 2002. Race, Real Estate, and Uneven Development: The Kansas City Experience, 1900-2000. SUNY Press.

Gould, Kenneth A., David N. Pellow, and Allan Schnaiberg. 2004. "Interrogating the Treadmill of Production: Everything You Wanted to Know about the Treadmill but Were Afraid to Ask." Organization \& Environment 17(3):296-316.

Hamilton, C. Horace and Josef Perry. 1962. "A Short Method for Projecting Population by Age from One Decennial Census to Another." Social Forces 41(2):163-70.

Hardy, R. Dean, Richard A. Milligan, and Nik Heynen. 2017. "Racial Coastal Formation: The Environmental Injustice of Colorblind Adaptation Planning for Sea-Level Rise." Geoforum 87:62-72.

Harlan, Sharon L., David N. Pellow, J. Timmons Roberts, Shannon Elizabeth Bell, William G. Holt, and Joane Nagel. 2015. "Climate Justice and Inequality." Climate Change and Society: Sociological Perspectives 127-63.

Hauer, Mathew E. 2017. "Migration Induced by Sea-Level Rise Could Reshape the US Population Landscape." Nature Climate Change 7(5):321-25.

Hauer, Mathew E. 2019. "Population Projections for U.S. Counties by Age, Sex, and Race Controlled to Shared Socioeconomic Pathway." Scientific Data 6:190005.

Hauer, Mathew E., Jason M. Evans, and Deepak R. Mishra. 2016. "Millions Projected to Be at Risk from Sea-Level Rise in the Continental United States." Nature Climate Change 6(7):691-95.

Heberger, Matthew, Heather Cooley, Pablo Herrera, Peter H. Gleick, and Eli Moore. 2011. "Potential Impacts of Increased Coastal Flooding in California Due to Sea-Level Rise." Climatic Change 109(S1):229-49.

Howell, Junia and James R. Elliott. 2019. "Damages Done: The Longitudinal Impacts of Natural Hazards on Wealth Inequality in the United States." Social Problems 66(3):448-67. 
Hsiang, Solomon, Robert Kopp, Amir Jina, James Rising, Michael Delgado, Shashank Mohan, D. J. Rasmussen, Robert Muir-Wood, Paul Wilson, and Michael Oppenheimer. 2017. "Estimating Economic Damage from Climate Change in the United States." Science 356(6345):1362-69.

Huntington, Henry P., Eban Goodstein, and Eugénie Euskirchen. 2012. "Towards a Tipping Point in Responding to Change: Rising Costs, Fewer Options for Arctic and Global Societies." AMBIO 41(1):66-74.

Hurley, Andrew. 1995. Environmental Inequalities: Class, Race, and Industrial Pollution in Gary, Indiana, 1945-1980. Univ of North Carolina Press.

Jesdale, Bill M., Rachel Morello-Frosch, and Lara Cushing. 2013. "The Racial/Ethnic Distribution of Heat Risk-Related Land Cover in Relation to Residential Segregation." Environmental Health Perspectives 121(7):811-17.

Jiang, Leiwen. 2014. "Internal Consistency of Demographic Assumptions in the Shared Socioeconomic Pathways." Population and Environment 35(3):261-85.

Justice, United Church of Christ. Commission for Racial. 1987. Toxic Wastes and Race in the United States: A National Report on the Racial and Socio-Economic Characteristics of Communities with Hazardous Waste Sites. Public Data Access.

Klein, Naomi. 2018. The Battle For Paradise: Puerto Rico Takes on the Disaster Capitalists. Haymarket Books.

Kopp, Robert E., Robert M. DeConto, Daniel A. Bader, Carling C. Hay, Radley M. Horton, Scott Kulp, Michael Oppenheimer, David Pollard, and Benjamin H. Strauss. 2017. "Evolving Understanding of Antarctic Ice-sheet Physics and Ambiguity in Probabilistic Sea-level Projections." Earth's Future 5(12):1217-33.

Kossin, James P. 2018. “A Global Slowdown of Tropical-Cyclone Translation Speed.” Nature 558(7708):104-7.

Krieg, Eric J. 1998. “The Two Faces of Toxic Waste: Trends in the Spread of Environmental Hazards.” Pp. 3-20 in Sociological Forum. Vol. 13. Springer.

Lefebvre, Henri and Donald Nicholson-Smith. 1991. The Production of Space. Vol. 142. Oxford Blackwell.

Liévanos, Raoul S. 2017. "Sociospatial Dimensions of Water Injustice: The Distribution of Surface Water Toxic Releases in California's Bay-Delta.” Sociological Perspectives 60(3):575-99.

Loftus, Alex. 2012. Everyday Environmentalism: Creating an Urban Political Ecology. U of Minnesota Press. 
Loughran, Kevin and James R. Elliott. 2019. "Residential Buyouts as Environmental Mobility: Examining Where Homeowners Move to Illuminate Social Inequities in Climate Adaptation." Population and Environment 41(1):52-70.

Martinich, Jeremy, James Neumann, Lindsay Ludwig, and Lesley Jantarasami. 2013. "Risks of Sea Level Rise to Disadvantaged Communities in the United States." Mitigation and Adaptation Strategies for Global Change 18(2):169-85.

Massey, Douglas S. and Nancy A. Denton. 1993. American Apartheid: Segregation and the Making of the Underclass. Harvard University Press.

McAlpine, Steven A. and Jeremy R. Porter. 2018. "Estimating Recent Local Impacts of SeaLevel Rise on Current Real-Estate Losses: A Housing Market Case Study in MiamiDade, Florida." Population Research and Policy Review 37(6):871-95.

McGranahan, Gordon, Deborah Balk, and Bridget Anderson. 2007. "The Rising Tide: Assessing the Risks of Climate Change and Human Settlements in Low Elevation Coastal Zones." Environment and Urbanization 19(1):17-37.

Mitchell, Gordon and Paul Norman. 2012. "Longitudinal Environmental Justice Analysis: CoEvolution of Environmental Quality and Deprivation in England, 1960-2007." Geoforum 43(1):44-57.

Mohai, Paul. 1996. "Environmental Justice or Analytic Justice? Reexamining Historical Hazardous Waste Landfill Siting Patterns in Metropolitan Texas." Social Science Quarterly 77(3):500-507.

Muller, Christopher, Robert J. Sampson, and Alix S. Winter. 2018. "Environmental Inequality: The Social Causes and Consequences of Lead Exposure.” Annual Review of Sociology 44(1):263-82.

Nagel, Joane. 2012. "Intersecting Identities and Global Climate Change.” Identities 19(4):46776.

Nicholls, Robert J., Natasha Marinova, Jason A. Lowe, Sally Brown, Pier Vellinga, Diogo de Gusmão, Jochen Hinkel, and Richard S. Tol. 2011. "Sea-Level Rise and Its Possible Impacts given a 'beyond $4{ }^{\circ} \mathrm{C}$ World' in the Twenty-First Century." Philosophical Transactions of the Royal Society A: Mathematical, Physical and Engineering Sciences 369(1934):161-81.

Norgaard, Kari Marie. 2011. Living in Denial: Climate Change, Emotions, and Everyday Life. MIT Press.

Oliver, Melvin and Thomas Shapiro. 2013. Black Wealth/White Wealth: A New Perspective on Racial Inequality. Routledge.

Omi, Michael and Howard Winant. 2014. Racial Formation in the United States. Routledge. 
O’Neill, Brian C., Elmar Kriegler, Kristie L. Ebi, Eric Kemp-Benedict, Keywan Riahi, Dale S. Rothman, Bas J. van Ruijven, Detlef P. van Vuuren, Joern Birkmann, Kasper Kok, and others. 2017. "The Roads Ahead: Narratives for Shared Socioeconomic Pathways Describing World Futures in the 21st Century." Global Environmental Change 42:16980.

O’Neill, Brian C., Elmar Kriegler, Keywan Riahi, Kristie L. Ebi, Stephane Hallegatte, Timothy R. Carter, Ritu Mathur, and Detlef P. van Vuuren. 2014. "A New Scenario Framework for Climate Change Research: The Concept of Shared Socioeconomic Pathways." Climatic Change 122(3):387-400.

Parks, Bradley C. and J. Timmons Roberts. 2010. "Climate Change, Social Theory and Justice." Theory, Culture \& Society 27(2-3):134-66.

Pastor, Manuel, Jim Sadd, and John Hipp. 2001. "Which Came First? Toxic Facilities, Minority Move-in, and Environmental Justice." Journal of Urban Affairs 23(1):1-21.

Pellow, David N. 2000. "Environmental Inequality Formation: Toward a Theory of Environmental Injustice." American Behavioral Scientist 43(4):581-601.

Pellow, David N. 2004. "The Politics of Illegal Dumping: An Environmental Justice Framework." Qualitative Sociology 27(4):511-25.

Pellow, David N. and Hollie Nyseth Brehm. 2013. "An Environmental Sociology for the Twenty-First Century." Annual Review of Sociology 39(1):229-50.

Pellow, David Naguib. 2017. What Is Critical Environmental Justice? John Wiley \& Sons.

Pellow, David Naguib and Robert J. Brulle. 2005. "Power, Justice, and the Environment: Toward Critical Environmental Justice Studies." Power, Justice, and the Environment: A Critical Appraisal of the Environmental Justice Movement 1-19.

Pulido, Laura. 2000. "Rethinking Environmental Racism: White Privilege and Urban Development in Southern California." Annals of the Association of American Geographers 90(1):12-40.

Pulido, Laura. 2017. "Geographies of Race and Ethnicity II: Environmental Racism, Racial Capitalism and State-Sanctioned Violence." Progress in Human Geography 41(4):52433.

Roberts, J. Timmons and Bradley C. Parks. 2009. "Ecologically Unequal Exchange, Ecological Debt, and Climate Justice: The History and Implications of Three Related Ideas for a New Social Movement." International Journal of Comparative Sociology 50(3-4):385409.

Rubinowitz, Leonard S. and James E. Rosenbaum. 2000. Crossing the Class and Color Lines: From Public Housing to White Suburbia. University of Chicago Press. 
Samir, KC and Wolfgang Lutz. 2017. "The Human Core of the Shared Socioeconomic Pathways: Population Scenarios by Age, Sex and Level of Education for All Countries to 2100." Global Environmental Change 42:181-92.

Schnaiberg, Allan. 1980. "Environment: From Surplus to Scarcity." in Environment: from surplus to scarcity. Oxford University Press.

Schnaiberg, Allan and Kenneth Alan Gould. 1994. Environment and Society : The Enduring Conflict. St. Martin's Press.

Sharkey, Patrick. 2013. Stuck in Place: Urban Neighborhoods and the End of Progress toward Racial Equality. University of Chicago Press.

Skoufias, Emmanuel. 2012. The Poverty and Welfare Impacts of Climate Change: Quantifying the Effects, Identifying the Adaptation Strategies. The World Bank.

Strauss, Benjamin H., Scott Kulp, and Anders Levermann. 2015. "Carbon Choices Determine US Cities Committed to Futures below Sea Level." Proceedings of the National Academy of Sciences 112(44):13508-13.

Suarez, Pablo, William Anderson, Vijay Mahal, and T. R. Lakshmanan. 2005. "Impacts of Flooding and Climate Change on Urban Transportation: A Systemwide Performance Assessment of the Boston Metro Area." Transportation Research Part D: Transport and Environment 10(3):231-44.

Swanson, David A., Alan Schlottmann, and Bob Schmidt. 2010. "Forecasting the Population of Census Tracts by Age and Sex: An Example of the Hamilton-Perry Method in Action." Population Research and Policy Review 29(1):47-63.

Szasz, Andrew and Michael Meuser. 1997. "Environmental Inequalities: Literature Review and Proposals for New Directions in Research and Theory." Current Sociology 45(3):99-120.

Szasz, Andrew and Michael Meuser. 2000. "Unintended, Inexorable: The Production of Environmental Inequalities in Santa Clara County, California." American Behavioral Scientist 43(4):602-32.

Taylor, Dorceta. 2014. Toxic Communities: Environmental Racism, Industrial Pollution, and Residential Mobility. NYU Press.

Taylor, Dorceta E. 2000. "The Rise of the Environmental Justice Paradigm: Injustice Framing and the Social Construction of Environmental Discourses." American Behavioral Scientist 43(4):508-80.

Taylor, Paul and Richard Allan Fry. 2012. The Rise of Residential Segregation by Income. Pew Research Center Washington, DC.

Tierney, Kathleen. 2015. "Resilience and the Neoliberal Project: Discourses, Critiques, Practices-And Katrina.” American Behavioral Scientist 59(10):1327-42. 
Tierney, Kathleen J. 2007. "From the Margins to the Mainstream? Disaster Research at the Crossroads." Annual Review of Sociology 33(1):503-25.

Wang, Chongming and Brent Yarnal. 2012. "The Vulnerability of the Elderly to Hurricane Hazards in Sarasota, Florida." Natural Hazards 63(2):349-73.

Wilson, Tom. 2016. "Evaluation of Alternative Cohort-Component Models for Local Area Population Forecasts." Population Research and Policy Review 35(2):241-61.

York, Richard, Eugene A. Rosa, and Thomas Dietz. 2003. "A Rift in Modernity? Assessing the Anthropogenic Sources of Global Climate Change with the STIRPAT Model." International Journal of Sociology and Social Policy 23(10):31-51.

Zehr, Stephen. 2015. “The Sociology of Global Climate Change.” Wiley Interdisciplinary Reviews: Climate Change 6(2):129-150. 